\title{
Local organization for sustainable rural development in a Malaysian village
}

\begin{abstract}
This case study of local organization established to organize development activities in a Malaysian village demonstrates the ability of local groups to sustain development. A mixed quantitative-qualitative methodology was used. Local organization was an important means of continuous economic and social development. Factors contributing to the perpetuation of local groups included acceptance by the community, institutionalization of the groups, able leadership, member gratification with group goals and functioning, ability of the groups to adapt to changing situations, democratic and self-management practices, and support from external agencies. It was concluded that local organization, with appropriate guidance from development agencies, can organize development efforts that are internally sustained by a community.
\end{abstract}

Keyword: Local group; Local organization; Malaysian village 